\title{
Incorporation of Oxygen in Crystalline Zeolitic Chromosilicates: Optical Identification of Chromium(vi) by Photoacoustic Spectroscopy
}

\author{
J. Silvio T. Mambrim, a Eduardo J. S. Vichi, ${ }^{*}$ a Heloise O. Pastore, ${ }^{a}$ Celso U. Davanzo, ${ }^{a}$ Helion Vargas, ${ }^{b}$ \\ Edson Silva ${ }^{b}$ and Ossamu Nakamura ${ }^{c}$ \\ a Instituto de Química, Universidade Estadual de Campinas, C. Postal 6154, 13081 Campinas, SP, Brazil \\ b Instituto de Física, Universidade Estadual de Campinas, 13081 Campinas, SP, Brazil \\ c Instituto de Física, Universidade Federal da Bahia, Salvador, BA, Brazil
}

Incorporation of oxygen to crystalline zeolitic chromosilicates, with oxidation of anchored $\mathrm{Cr}$ 'll to non-interacting $\mathrm{Cr}$ 'VI species, has been confirmed by photoacoustic spectroscopy; the dichromate anion being extracted from the chromosilicate with water and identified by precipitation of $\mathrm{AgCrO}_{4}$ and oxidation to $\mathrm{CrO}_{5}$.

The study of the state of chromium ions in high-content silica zeolites is of great interest since new polyfunctional catalysts can be designed with these systems. ${ }^{1}$ It was recently shown that both $\mathrm{Cr}^{\mathrm{III}}$ and $\mathrm{Cr}^{\mathrm{V}}$ ions can be incorporated in the cationic positions of zeolites of the ZSM-5 type. ${ }^{2}$

In a recent communication ${ }^{3}$ we reported on the preparation of a highly crystalline zeolitic chromosilicate containing $\mathrm{Cr}^{\mathrm{III}}$ both in framework, and non-framework positions, the latter probably anchored inside the channels and forming species similar to $\mathrm{Cr}_{2} \mathrm{O}_{3}$. Here we report on the obtention of $\mathrm{Cr} V \mathrm{VI}$ species during the process of calcination of this chromosilicate.

After heating a sample of this chromosilicate at $693 \mathrm{~K}$ for $24 \mathrm{~h}$, in a shallow bed, under an oxygen flow, its colour 


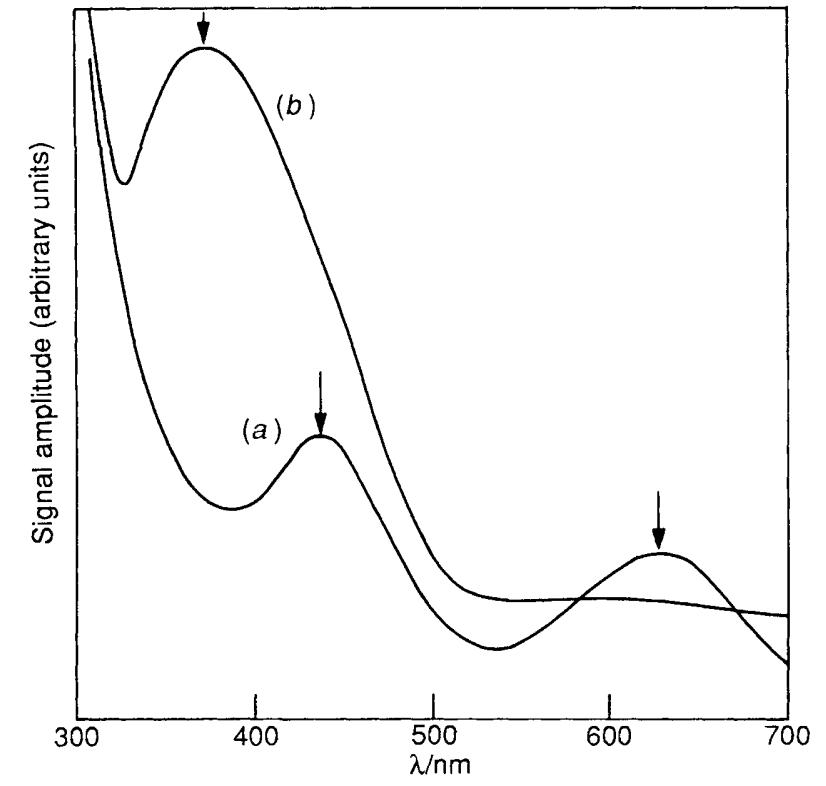

Fig. 1 PAS spectra of chromium in crystalline zeolitic chromosilicates, (a) ligand field bands of $\mathrm{Cr}^{\mathrm{III}},(b)$ charge transfer band of $\mathrm{Cr}^{\mathrm{VI}}$

changed from light green to yellow. The presence of $\mathrm{Cr}$ VI, was detected by means of photoacoustic spectroscopy (PAS), which is rapidly achieving importance as a technique for obtaining ultraviolet, visible and near-infrared absorption of opaque or highly scattering samples such as powders, glasses, gels and turbid liquids. ${ }^{4}$ The recorded spectrum is identical to that from conventional spectroscopic techniques. ${ }^{5}$

The spectrum of a freshly prepared sample of the chromosilicate is shown in Fig. 1( $a$ ), and is characterized by two bands centred at 440 and $640 \mathrm{~nm}$, respectively, corresponding to ligand field bands of $\mathrm{Cr}^{\mathrm{III}}$. For the level assignment ${ }^{6}$ the band centred at $440 \mathrm{~nm}$ is interpreted as the ${ }^{4} \Gamma_{2} \rightarrow{ }^{4} \Gamma_{4}$ (F) transition, and the band at $640 \mathrm{~nm}$ is interpreted as the ${ }^{4} \Gamma_{2} \rightarrow$ ${ }^{4} \Gamma_{5}$ transition. Fig. $1(b)$ shows the spectrum of the same sample after being treated with oxygen as previously described. A strong band at $370 \mathrm{~nm}$ is clearly seen, which is assigned to a charge transfer absorption of $\mathrm{Cr}$ VI. The second charge transfer occurring at $270 \mathrm{~nm}$ was not observed since our equipment (an EDT-model OAS spectrometer) is limited to the range of 300 to $700 \mathrm{~nm}$.

Fig. 2 shows the IR spectra of (a) the original sample, $(b)$ the sample treated with oxygen at $693 \mathrm{~K}$, and $(c)$ the sample treated with dioxygen at $843 \mathrm{~K}$. The sample calcined at $693 \mathrm{~K}$ retained its zeolitic crystal structure as shown by the $550: 440 \mathrm{~cm}^{-1}$ optical density ratios equal to 0.77 , for $(a)$, and 0.74 for $(b)$. However, heating the sample at $843 \mathrm{~K}$ leads to the collapse of the crystal structure of the pentasil zeolites, as shown by the disappearance of the peaks at 550 and $450 \mathrm{~cm}^{-1}$ [Fig. 2(c)].

The yellow colour of the calcined chromosilicate strongly suggests that $\mathrm{Cr}^{\mathrm{VI}}$ is bonded to extraframework $\mathrm{O}^{2-}$ ligands forming anionic species like $\mathrm{CrO}_{4}{ }^{2-}$ or $\mathrm{Cr}_{2} \mathrm{O}_{7}{ }^{2-}$. It is probable that the anchored and activated $\mathrm{Cr}_{2} \mathrm{O}_{3}$ species incorporate oxygen to form $\mathrm{CrO}_{3}$ which is then hydrolysed during the rehydration of the zeolite. In fact, washing the sample with cold water leads to the easy and almost quantitative extraction of the chromates. The chromates were identified in the extracts by the precipitation of the reddish-brown $\mathrm{Ag}_{2} \mathrm{CrO}_{4}$

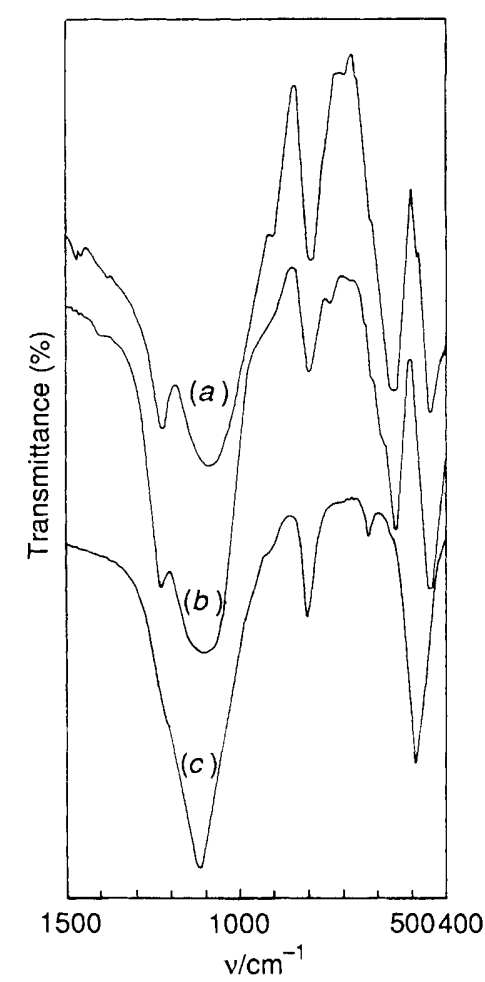

Fig. 2 IR spectra of $(a)$ the original chromosilicate sample, $(b)$ the sample treated with oxygen at $693 \mathrm{~K},(c)$ the sample treated with oxygen at $843 \mathrm{~K}$

after addition of an aqueous solution of $\mathrm{AgNO}_{3}$, and by the formation of blue $\mathrm{CrO}_{5}$, in diethyl ether, after addition of $3 \%$ hydrogen peroxide and dilute $\mathrm{HNO}_{3}{ }^{7}$

The retention of the zeolitic crystal structure upon heating to $693 \mathrm{~K}$ suggests that, at this temperature, only the extraframework $\mathrm{Cr}^{11 I}$ ions react with oxygen producing chromates. It is impossible to say, at this stage, if the breakdown of the zeolitic framework, at $843 \mathrm{~K}$, is caused by thermal expulsion of $\mathrm{Cr}^{\mathrm{III}}$ from the silicon lattice or by thermal activation towards oxygen attack.

We are investigating the dehydration/rehydration processes and the reversibility of the oxidation process in an attempt to explore all the potentialities of this very interesting system.

We gratefully acknowledge FAPESP and CNPq for financial support.

\section{Received, 13th February 1991; Com. 1/00685A}

\section{References}

1 R. B. Borade, A. B. Halgeri, and T. S. R. P. Rao, Advances in Catalysis Science and Technology, Wiley Eastern, New Delhi, 1985, p. 389.

2 A. V. Kucherov and A. A. Slinkin, Zeolites, 1987, 28, 81; A. V. Kucherov and A. A. Slinkin, Kinet. Katal., 1986, 27, 1199.

3 H. O. Pastore, E. Stein, C. U. Davanzo, E. J. S. Vichi, O. Kakamura, M. Baesso, E. Silva and H. Vargas, J. Chem. Soc., Chem. Commun., 1990, 772.

4 H. Vargas and L. C. M. Miranda, J. Phys. Rep., 1988, 161; 245.

5 A. Rosencwaig, Photoacoustics and Photoacoustic Spectroscopy, Wiley, New York, 1980.

6 Y. Tanabe and S. Sugano, J. Phys. Soc. Jpn., 1954, 9, 753; 766.

7 I. Vogel, Textbook of Macro and Semimicro Qualitative Inorganic Analysis, Longman, London, 5th edn., 1979, p. 361 and 362. 